\title{
Mortality and Morbidity in Elective Patient of Coronary Artery Bypass Graph at National Cardiovascular Center, Harapan Kita Hospital, Indonesia
}

\author{
Hartaty Sarma Sangkot ${ }^{1} \&$ Puguh Yudho Trisnanto $^{2}$ \\ ${ }^{1}$ Malang State Health Polytechnic, Malang, Indonesia \\ Correspondence: Hartaty Sarma Sangkot Malang State Health Polytechnic, Malang, Indonesia 65112. Tel: 62- \\ 821-7533-5738. E-mail: hartatysarma@gmail.com
}

Received: November 1, 2019; Accepted: December 11, 2019; Published: December 12, 2019

The research is financed by (Sponsoring information).

\begin{abstract}
This study is aimed to find out mortality and morbidity in the elective patients while waiting and description of waiting time in elective patients at The Department of cardiovascular surgery, Harapan Kita Hospital. This study research was using quantitative and qualitative design study. The quantitative data collected prospectively within two months from August until September 2010. From 58 patients, one patient died while waiting and one patient falls into stroke. There's no adequate system in scheduling patient, including put the patient into the list of que, decide the urgency and remove the patients from the list. It's known that morbidity and mortality are not found as a significant event happened while waiting for CABG in this study. It's difficult to ignore the two patients, especially after knowing there's no adequate system to decide wait time and schedule at The Department of cardiovascular surgery, Harapan Kita Hospital, while resources are still quite enough (facility and human resources) to accommodate all the cases.
\end{abstract}

Keywords: waiting time, scheduling, mortality, morbidity

\section{Introduction}

\subsection{Introduce the Problem}

Cardiovascular disease still becomes the leading cause of mortality globally. It was estimated that approximately 17.5 million people worldwide die because of cardiovascular disease in 2012, which is about $31 \%$ of 51,5 million people (World Health Organization Regional Office for South-East Asia and the Pacific, 2017).It was also estimated in 2030, about 23,6 million people will die because of cardiovascular disease, mainly because of heart disease and stroke. The highest percentage of cardiovascular disease will be in East Mediterania, while increasing mortality will occur in Southeast Asia (WHO, 2009). Indonesia, as one of the countries in Southeast Asia, should aware of this global issue. System Registration Sample Survey (SRS) in 2014 showed Coronary Heart Disease as the leading cause of all mortality in all ages after stroke. Riskesdas(BasicHealth Research in Indonesia)in2013 mentionsthat 3(three) highest diseases that lead to death are heart disease, cancer, and stroke (Kementerian Kesehatan RI, 2017).

Coronary Artery Bypass Graph (CABG) is one of the most frequent surgical procedures worldwide(Rexius etal.,2006a).Despitealargenumberofsurgical procedures, there is an imbalance between needs and resource to full this procedure which leads to waiting time of surgical (Lau et al., 2007), giving priority within patients (Bono et al., 1998), and mortality within the patient while waiting list. (Koomen, 2001). These phenomena not only happened in Indonesia but also around the world. A list of long waiting times for CABG already reported from all over the world, such as in Sweden, Canada, New Zealand, Great Britain, and Netherland (Rexius et al., 2006a).

Waiting time was identified relates to several disadvantages such as morbidity, risk factor, life quality, anxiety, andalsostressinpatients. PatientMorbidity in waiting time usually relates to revascularization delays such as stroke, myocardialinfarction, andangina pectoris attack. Delay in revascularization inpatient CABG with ischemic left ventricular dysfunction showing the decrease of heart function and the possibility of 
contractility repair(Rexius et al., 2005). Moreover, waiting time is an independent factor for mortality risk impatientwhilewaiting. A study show, extensive waitingperiods for CABG contribute to higher mortality and morbidity rates, especially in patients with left ventricular dysfunction (da Fonseca, De Lorenzo, Tura, Pittella, \& da Rocha, 2018). Perioperative mortality could be hindered by shortening waiting time. However, a study conducted by Rayand college (Ray, Buth, Sullivan, Johnstone, \& Hirsch, 2001)(Ray et al., 2017) shows that death and upgrades while the patients were waiting tended to occur early In the queuing process, and prolonged waiting, was not associated with worse surgical outcomes.

Based on the annual report released by National Cardiovascular Center Harapan Kita Hospital, the number of cases of surgical procedure in 2008 generally almostreach 1.821 cases. Furthermore, thenumberincrease in 2009 become 1.904 cases. Specif i cally, there is an increase in coronary case number from 660 cases in 2008 become 750 cases in 2009 . This increase is a trend that will continually happen in the future in line with the change of lifestyle and disease pattern in Indonesia society. The increase of case number is not accompanied by the increase of supporting resources number, so imbalance comparison between needs and fulfillment leads to waiting time before the operation. Nowadays, there are three operation theaters for adult surgical and two operation theaters for child procedure to handle all the cases in the National CardiovascularCenterHarapan Kita Hospital. Relate to the human resource; there are nine thoracic and cardiovascular surgeons ( 6 specialists in adult and 3 specialists in the child). Meanwhile, there is still no data about waiting time, such as a mean for waiting for time and mortality and morbidity while waiting.

The purpose of this study was to find out mortality and morbidity in elective patient while waiting and description of waiting time in elective patient related to resources needed (system, human resources and facility) at department of cardiovascular surgery, National Cardiovascular Center Harapan Kita Hospital as the only one referral center for cardiovascular case in Indonesia.

\section{Method}

\subsection{Research Study}

This study was conducted at Department of cardiovascular surgery, National Cardiovascular Center Harapan Kita Hospital, as the referral center for cardiovascular case in Indonesia. The aim of this study was to find out the mortality and morbidity of the elective patients while waiting for Coronary Artery Bypass Graph (CABG) procedure. The study using both quantitative and qualitative studies.

The population in this study was all the patients at a department of cardiovascular surgery, National Cardiovascular Center Harapan Kita Hospital, who diagnosed with coronary heart dysfunction. These patients then consulted with Thoracic and Cardiovascular Surgery to have Coronary Artery Bypass Graph (CABG) procedure only without any other procedure in the National CardiovascularCenter Harapan Kita Hospital. The sample of this study was all the elective patients during August-September 2010 who fulfilled inclusion and exclusion criteria. Inclusion criteria were all patients with coronary heart disease without any hemodynamic instability and out of emergency category patient (emergency) to operated. Exclusion criteria were patients with coronary heart disease who need emergency CABG plus other heart surgical procedures. This study was conducted in the National Cardiovascular Center Harapan Kita Hospital, specifically in the department of adult cardiovascular surgery and central ward, 2nd floor, Building 1 from August until November 2010. Treatment The data collected in this study was secondary. There were several sources, such as the book of schedule, registration book, nursing notes, and medical record. Qualitative data collection was done by depth interview, observation of scheduling activity, and documentation review. The period of data collection was from August until November 2010. All this activity was done in the department of cardiovascular surgery and intermediate ward. The instrument which was used in the qualitative design is the patient observation checklist, which self-fulfilled by a researcher. Meanwhile, the instrument used in-depth interview is a list of questions base on the topic discussed and checklist for observation.

There are two types of data analysis for this study depend on the kind of data. Quantitative data were analyzed by univariate analysis to nd out the description of distribution frequency (numeric variable) and description of descriptive, which is a proportion (categorical variable). In addition, qualitative data were analyzed manually by writing the result of the study into the transcriptofdepthinterviewresultsthen summarized into a matrix. The matrix will be written in a formal language based on the statement of the informant. This summary then transformed into the narration and resumed into a description, which already received generally. 


\section{Result}

\section{a. The General condition of patients}

In the beginning, there were about 85 patients included in the inclusion criteria. Nevertheless, then in progress, there were 27 patients canceled and only 58 patients who finally planned to standard CABG procedure. The average patient's age was 57.8 , with a deviation standard of 7.7 . The youngest patients were 40 years old, while the oldest was 78 years old

Table 1. Characteristic of Patient (Sex and Body Mass Index)

\begin{tabular}{lccc}
\hline VARIABEL & $\begin{array}{c}\text { Frek } \\
\mathbf{n}(\mathbf{n}=\mathbf{5 8})\end{array}$ & $\mathbf{\%}$ \\
\hline Sex & & \\
& Male & 55 & 94,8 \\
& Female & 3 & 5,2 \\
\hline Body Mass Index & & \\
& Underweight & 2 & 3,4 \\
& Normal & 33 & 56,9 \\
Overweight & 15 & 25,9 \\
Obesities & 8 & 13,8 \\
\hline
\end{tabular}

In this study, the data collected only about the patient's general condition, which influences the waiting time. The result is shown in table 2 that the averagebloodvesseldysfunctioninpatientis 2.9 withdeviation standard 0.4. Average of left ventricle dysfunction, known as Ejection Fraction (EF), is 54 with deviation standard 13.5. From all the total patient $(\mathrm{n}=58)$, only about $1,7 \%(\mathrm{n}=1)$ patient with renal failure. There are about $3,4 \%(\mathrm{n}=2)$ patients with cerebrovascular disease. Patient with diabetes mellitus risk factor was about $31 \%$ $(\mathrm{n}=18)$. All patients in this study received CABG surgical procedure for the first time. About $8,6 \%(\mathrm{n}=5)$ patients who receive this procedure already throughPCI(PercutaneousCoronaryIntervention)previously. Therewas $74,1 \%$ $(\mathrm{n}=43)$ patient with angina pectoris. Moreover, based on the type, there was $86,4 \%(\mathrm{n}=37)$ withstableandtherest $13,6 \%(n=6)$ was unstable. About $24,1 \%(n=14)$ patient was in left main dysfunction and about $1,7 \%(n=1)$ patientwas had stroke before the procedure.

Table 2. General Description of Patient's Clinical Condition

\begin{tabular}{|c|c|c|}
\hline \multirow[t]{2}{*}{ VARIABEL } & \multicolumn{2}{|c|}{ Total $(n=58)$} \\
\hline & $\mathbf{N}$ & $\%$ \\
\hline Renal Failure & 1 & 1,7 \\
\hline PPOK & 0 & 0 \\
\hline Cerebrovaskular Disase & 2 & 3,4 \\
\hline Diabetes Melitus & 18 & 31 \\
\hline Aorta Stenosis & 0 & 0 \\
\hline Mitral Stenosis & 0 & 0 \\
\hline Trikuspid Stenosis & 0 & 0 \\
\hline Pulmonal Stenosis & 0 & 0 \\
\hline Aorta Insufficiency & 0 & 0 \\
\hline \multicolumn{3}{|l|}{ Mitral Insufficiency } \\
\hline Trivial & 6 & 10,3 \\
\hline Mild & 3 & 5,2 \\
\hline Moderate & 1 & 1,7 \\
\hline \multicolumn{3}{|l|}{ Trikuspid Insufficiency } \\
\hline Trivial & 4 & 6,9 \\
\hline Mild & 2 & 3,4 \\
\hline $\begin{array}{l}\text { Pulmonal Insufficiency } \\
\text { Risk }\end{array}$ & 0 & 0 \\
\hline Low & 44 & 75,9 \\
\hline Medium & 14 & 24,1 \\
\hline
\end{tabular}




\begin{tabular}{lcc}
\hline First CABG Procedure & 58 & 100 \\
PCI history & 5 & 8,6 \\
Pacemaker history & 1 & 1,7 \\
Angina Pectoris & 43 & 74,1 \\
$\quad$ Stable & 37 & 86,4 \\
Unstable & 6 & 13,6 \\
Left Main & 14 & 24,1 \\
Stroke Preop & 1 & 1,7 \\
Infark Miokard Preop & 0 & 0 \\
\hline
\end{tabular}

\section{a. Waiting time}

As mentioned previously, there were 85 patients included in the inclusion criteria. Moreover, about 27 patients was canceled because of several reasons such as: 1 patient had stroke, patient's clinical condition getting worst so he has to be rescheduled, patients need other procedure (such as PTCA or PCI), patients didn't ready to receive the procedure so they didn't show up at the d day of procedure and move to another hospital. The Median of waiting time was 14 days. The fastest waiting time was five days and the longest was 41 days. Base on the depth interview, clinically waiting time was influenced by emergencies of a patient and also their general condition. Furthermore, almost all informants in management said that waiting time was influenced by the number of patients register, the complexity of case, numbers of surgeons available, numbers of operating theater, numbers of beds in ICU and numbers of the ward. The informant also said that priority is already given for patients who will receive the surgical procedures. Patients with priority, mainly because of their clinical condition and also because they had come from out of the city. Unfortunately, there still no Standard Operational Procedure (SOP) which regulates waiting time.

There were several reasons to determine whether the procedure needs to be urgent(cito)orelective. Theyare thegeneralconditionofthepatientwhenthey come to the hospital (acute and have a particular case), the period from the first-time attack until the surgical procedure (stable or unstable). Moreover, there is already SOP to regulate the emergency surgical procedure (urgent). However, in that document, there is no specific condition to mention whether a patient needs urgent surgical or not; it was only in general that mentioned urgentprocedure needediftheconditionlife threatened. Allinformants said that waiting time was determined by the head of functional service, department of cardiovascular, while administrative staff assist him in receiving the consultation then giving schedule base on que and the schedule available. The study shows there still no optimalstandard of waiting time used in the NationalCardiovascularCenter,HarapanKitaHospital.BaseonThe Canadian Cardiovascular Society, the ideal of waiting time is 14 days. Base on it, researchersclassify waiting time in this hospital into two categories, ideal waiting time and unideal. From 57 patients, about $50,9 \%(\mathrm{n}=29)$ patient receives surgical procedure within 14 days(ideal) while therest 28 peoples $(49,1 \%)$ receive the procedure for more than 14 days. Base on qualitative data, almostall informants said that there was already evaluation to determine waiting time. Half of the informants feel optimistic that base on the result of the evaluation, management of hospitals would add more resources in the operating theater, so queuing and waitingtimecanbedecreased.Recently, based on more than half of informants, there was a plan to add one more adult theater and bed in ICU. Meanwhile, some informants said even evaluation was received. Still, no solution has taken yet. There is still a problem coming when the urgent patient needs to operate while the schedule was full of elective patients. It was hard sometimes to do the urgent procedure or finally sacrifice elective patients on that day.

\section{Discussion}

\section{a. Description of Characteristic and Clinical Condition of Respondent}

Base on analyzing of respondent characteristics, a patient who receive CABG procedure, tend to be younger compared to previous years. In the latest study, the average age of the patient was above 60 y.o, 66 y.o(Rexius etal., 2006b), or 64 y.o (Koomen, 2001). The fact that number of male patients bigger don't suit the fact that incidence of cardiovascular study was balanced between male and female(WHO, 2009), however, this study wasconsistentwithMorganand college who was studied more than 29.000 patient in wait time and nd out that age, gender and left ventricle dysfunction was independent risk for mortality(Rexiusetal.,2006a). Theresult that more patients had normal BMI doesn't support other studies that overweight is an indicator of hyperlipidemia and risk factor for coronary heart disease (Jackson et al., 1999). 
The study shows that the average number of a dysfunction blood vessel inpatient was 2.9 or almost 3 , which was a maximal number in criteria of blood vessel dysfunction. An average number of Ejection Fraction(EF) was $54 \%$. A classification, which was done by another study, shows that EF scores $\geq 50 \%$ got scoring 0 as a predictor for giving priority to $\mathrm{CABG}$ procedure, while $\mathrm{EF}$ scores $\leq 35 \%$ was the highest-scoring to receive surgical procedure(Jackson et al., 1999).

There were about $73,1 \%(\mathrm{n}=43)$ patients with angina pectoris. Furthermore, based on type there was $86,4 \%$ $(\mathrm{n}=37)$ with stable condition and the rest was $13,6 \%(\mathrm{n}=6)$ in unstable condition. According to the distribution in waiting time, patients with stable angina pectoris more likely had not ideal waiting time, which is about $95,2 \%(n=20)$, and patients with unstable angina pectoris more likely had ideal waiting time. The previous study conducted by Naylor and college(Nayloretal.,2000)identified threemaindeterminants toinfluence the urgency of giving CABG procedure, they are severity, angina symptom, the anatomy of the coronary and invasivetestresultforangina. Therewas $24,1 \%(\mathrm{n}=14)$ patient had left main dysfunction and about $1,7 \%$ $(\mathrm{n}=1)$ patient got strokeoncebeforethesurgicalprocedure. Baseontheavailabilityofleftmain dysfunction impatient while waiting, the patient left the main dysfunction more likely in a position of ideal waiting time $(31 \%, \mathrm{n}=9)$. This fact is not consistent with the previously studied, which gives higher urgency to the patient withleft main dysfunction. The latest study shows that patient with left main dysfunction (main left branch) and worst left ventricle function leads to a bigger risk factor to mortality, especially during the surgical procedure because it was the most importantpredictortoknowsurvivalrate(Jacksonetal., 1999). Base on risk factors related to mortality and morbidity in waiting time, these patients should be in elective surgical and not in the urgent procedure.

\section{b. Wait Time}

The result of this study shows that wait time in the National Cardiovascular Center, Harapan Kita hospital faster compared with wait time in the previous studies such as in Australia and Europe. Four other mortality has happened after the operation while the patient still in hospitalization. The reasons for thosepatientsare $75 \%$ $(n=3)$ becauseofclinicalproblemsrelated toaheart condition and $25 \%(n=1)$ because of infection after operated. Even though this studydidn'tconductfurtherbivariateanalyze to ndoutrelationshipbetween wait time and mortality and morbidity, and also other study shows that wait time is not predictive independent for the increaseofmortality(Legareetal., 2005), in fact it's hard to ignore the fact that there is 1 patient out of 57 who died and 1 patient out of 57 who had complication while waiting for $C A B G$ procedure.

\section{Acknowledgments}

The short period to conduct this study lead to a limited number of the sample, which could be studied and also the phenomena of mortality and morbidity in patients. This study uses longitudinal design during 2 (two) months studied so that the result could not be generalized as what tends to have happened in the Department of Cardiovascular,NationalCardiovascularCenter,Harapan Kita Hospital, especially which related to mortality and morbidity. Furthermore, there was no exploration of race, socio-economy condition, and alternative medication, which also suspected as one of the reasons schedule change and waiting time.

\section{References}

Bono, D. P. D., Ravilious, B., El-Zoubi, I., Dyer, T., \& Podinovskaya, Y. (1998). A Prioritisation System for Elective Coronary Angiography. Heart, 79, 448-453. https://doi.org/10.1136/hrt.79.5.448

da Fonseca, V. B. P., De Lorenzo, A., Tura, B. R., Pittella, F. J. M., \& da Rocha, A. S. C. (2018). Mortality and morbidity of patients on the waiting list for coronary artery bypass graft surgery. Interactive Cardiovascular and Thoracic Surgery, 26(1), 34-40. https://doi.org/10.1093/icvts/ivx276

Jackson, N. W., Doogue, M. P., \& Elliott, J. M. (1999). Priority Points And Cardiac Events While Waiting for Coronary Bypass Surgery. Heart, 81, 367-373. https://doi.org/10.1136/hrt.81.4.367

Kementerian, K. R. I. (2017). Penyakit Jantung Penyebab Kematian Tertinggi. Kementrian Kesehatan Republik Indonesia, 2015-2016.

Koomen, E. M. (2001). Morbidity and Mortality In Patients Waiting For Coronary Artery Bypass Surgery. European Journal of Cardio-Thoracic Surgery, 19, 260-265. https://doi.org/10.1016/S1010-7940(01)005802

Lau, R., Vair, B. A., \& Porter, G. A. (2007). Factors Influencing Waiting Times for Elective Laparoscopic Cholecystectomy. Canadian Journal of Surgery, 50(1), 34-38.

Legare, J. F., Maclean, A., J., Buth, K., \&Sulivan, A. J. (2005). Assesing The Risk of Waiting for Coronary Artery 
Bypass Graft Surgery Among Patients With Stenosis of the Left Main Coronary. Can. Med. Assoc. J., 173, 371-375. https://doi.org/10.1503/cmaj.050053

Naylor, C. D., Szalai, J. P., \& Katic, M. (2000). Benchmarking The Vital Risk of Waiting for Coronary Artery Bypass Surgery in Ontario. Can. Med. Assoc. J., 162, 775-779.

Ray, A. A., Buth, K. J., Sullivan, J. A., Johnstone, D. E., \& Hirsch, G. M. (2001). Waiting for cardiac surgery results of a risk-stratified queuing process. Circulation, 104(SUPPL. 1), 92-98. https://doi.org/10.1161/hc37t1.094904

Rexius, H., Brandrup-Wognsen, G., Nilsson, J., Odén, A., \& Jeppsson, A. (2006a). A Simple Score to Assess Mortality Risk In Patients Waiting for Coronary Artery Bypass Grafting. Ann Thorac Surg, 81, 577-582. https://doi.org/10.1016/j.athoracsur.2005.08.032

Rexius, H., Brandrup-Wognsen, G., Odén, A., \& Jeppsson, A. (2005). Waiting Time And Mortality after Elective Coronary Artery Bypass Grafting. The Annals of Thoracic Surgery, 79(2), 538-543. https://doi.org/10.1016/j.athoracsur.2004.07.029

WHO, M. C. (2009). Cardiovascular Center [Online]. [Accessed June 23rd 2010].

World Health Organization Regional Office for South-East Asia and the Pacific. (2017). From vision to results: Advancing health for billions in the South-East Asia Region.

\section{Copyrights}

Copyright for this article is retained by the author(s), with first publication rights granted to the journal.

This is an open-access article distributed under the terms and conditions of the Creative Commons Attribution license (http://creativecommons.org/licenses/by/4.0/). 